\title{
A systematic review of electronic audit and feedback: intervention effectiveness and use of behaviour change theory
}

Timothy Tuti ${ }^{*}$ (D), Jacinta Nzinga ${ }^{1}$, Martin Njoroge ${ }^{1}$, Benjamin Brown ${ }^{3}$, Niels Peek ${ }^{3,5}$, Mike English $^{1,2}$, Chris Paton ${ }^{2}$ and Sabine $\mathrm{N}$ van der Veer ${ }^{3,4}$

\begin{abstract}
Background: Audit and feedback is a common intervention for supporting clinical behaviour change. Increasingly, health data are available in electronic format. Yet, little is known regarding if and how electronic audit and feedback (e-A\&F) improves quality of care in practice.

Objective: The study aimed to assess the effectiveness of e-A\&F interventions in a primary care and hospital context and to identify theoretical mechanisms of behaviour change underlying these interventions.

Methods: In August 2016, we searched five electronic databases, including MEDLINE and EMBASE via Ovid, and the Cochrane Central Register of Controlled Trials for published randomised controlled trials. We included studies that evaluated e-A\&F interventions, defined as a summary of clinical performance delivered through an interactive computer interface to healthcare providers. Data on feedback characteristics, underlying theoretical domains, effect size and risk of bias were extracted by two independent review authors, who determined the domains within the Theoretical Domains Framework (TDF). We performed a meta-analysis of e-A\&F effectiveness, and a narrative analysis of the nature and patterns of TDF domains and potential links with the intervention effect.

Results: We included seven studies comprising of 81,700 patients being cared for by 329 healthcare professionals/ primary care facilities. Given the extremely high heterogeneity of the e-A\&F interventions and five studies having a medium or high risk of bias, the average effect was deemed unreliable. Only two studies explicitly used theory to guide intervention design. The most frequent theoretical domains targeted by the e-A\&F interventions included 'knowledge', 'social influences', 'goals' and 'behaviour regulation', with each intervention targeting a combination of at least three. None of the interventions addressed the domains 'social/professional role and identity' or 'emotion'. Analyses identified the number of different domains coded in control arm to have the biggest role in heterogeneity in e-A\&F effect size.

Conclusions: Given the high heterogeneity of identified studies, the effects of e-A\&F were found to be highly variable. Additionally, e-A\&F interventions tend to implicitly target only a fraction of known theoretical domains, even after omitting domains presumed not to be linked to e-A\&F. Also, little evaluation of comparative effectiveness across trial arms was conducted. Future research should seek to further unpack the theoretical domains essential for effective e-A\&F in order to better support strategic individual and team goals.
\end{abstract}

Keywords: Theory, Behaviour and behaviour mechanisms, Meta-analysis, Medical audit, Feedback, Performance, User-computer interface

* Correspondence: TTuti@kemri-wellcome.org

${ }^{1}$ KEMRI-Wellcome Trust Research Programme, Nairobi, Kenya

Full list of author information is available at the end of the article 


\section{Background}

\section{Electronic audit and feedback}

Audit and feedback (A\&F) defined as the provision of clinical performance summaries to healthcare providers and organisations [1] is a well-used approach to support clinical behaviour change [2]. The increasing availability of health data in an electronic format (e.g. in Electronic Health Records), significantly increases potential for use of these data to provide electronic A\&F (e-A\&F).

$\mathrm{e}-\mathrm{A} \& \mathrm{~F}$ can be defined as the utilisation of interactive computer interfaces to provide clinical performance summaries to healthcare professionals [1, 3-7]. It aims to support the decision-making process or guide team management [3-7]. Although A\&F is generally used when the patient is not present (e.g. like in bedside consultations, thereby making it distinctly different from computerized clinical decision support tools), e-A\&F interventions specifically target clinicians or their managers and can aid improvement of patient care by providing timely or even real-time information for decision-making as part of operational management [8]. Furthermore, the interactive computer interface may allow users to filter, drill down and further explore their performance summaries.

Mechanisms of how A\&F leads to behaviour change are variable and largely ignored in both individual and team-based contexts $[9,10]$. While individual-based feedback is desirable [11], feedback to providers organised in teams or organisational units (e.g. whole facilities or departments) may offer a more scalable implementation model appropriate for low- and middle-income contexts [12]. In team-based care, multiple healthcare professionals are responsible for the same patients, and complex coordination is required [13]. Given previous A\&F research showing team processes to explain more variance in outcome than practice structure[14], e-A\&F interventions might additionally better facilitate improvement in teambased settings by addressing the aforementioned features.

\section{Use of theory}

A\&F is posited to increase accountability and quality of care through implicit behaviour regulation of healthcare professionals [9]-given it involves techniques of goal setting, monitoring and providing feedback [15] —and is postulated to be most effective when its design is guided by theory $[9,16,17]$. However, explicit use of theory in A\&F interventions is scarce [18]. As a consequence, little is known on the more specific topic of how e-A\&F interventions may enhance the quality of care.

It is noteworthy that barriers to behaviour change can be influenced by A\&F [19] and that these barriers differ across clinicians, originating from differences in clinicians' training, knowledge, work experience, personality and other individual characteristics. These barriers are complex and dynamic (they are influenced by ongoing changes in the healthcare organization which in turn influence clinicians' behaviours) [20]. Use of theory can help direct predictions on the effect size of audit and feedback used to help clinicians' behaviour change.

A\&F interventions with graphical or written presentations, to our knowledge, provide feedback in the same format for all recipients. In this way, $A \& F$ is not sensitive to individual differences in barriers to behaviour change given the media platform. e-A\&F could help address this individual-indifferent approach in applying theory to overcome this significant limitation for traditional A\&F presentations [21].

However, when explicit theory underlying implementation interventions is absent, it may be possible to retrospectively identify the theoretical domains they were likely to target [22]. This can be achieved through use of broad theoretical frameworks, such as the Theoretical Domains Framework (TDF) [22, 23]. The TDF comprises 12 theoretical domains and 128 constructs from 33 behaviour change theories. It was developed using an expert consensus and validation process to identify an agreed set of theoretical domains that could be used in developing implementation interventions [22, 23].

We expect knowledge, skills, social/professional role and identity, beliefs about capabilities, environmental context and resources, beliefs about consequences, motivation and goals, behavioural regulation and nature of the behaviours and social influences TDF domains to be inherently targeted by e-A\&F interventions. This expectation is informed by component theories such as normalisation process theory $[24,25]$ theory of planned behaviour [26] and control theory [27]. Our detailed justification for the selection of these domains is provided in Additional file 1. However, we are yet to come upon literature detailing how emotion domain was targeted by electronic quality improvement initiatives. Based on the context, not all domains might be relevant in all e-A\&F interventions.

Identifying and summarising the theoretical concepts targeted by e-A\&F interventions for primary and hospitalbased care and exploring how these factors might influence the interventions' effectiveness could contribute to better e-A\&F design. Ultimately, this may lead to e-A\&F to become a more reliable approach to improving the quality of clinical practice.

\section{Aim and objectives}

We aimed to conduct a systematic review and metaanalysis of randomised controlled trials that evaluated the effectiveness of $\mathrm{e}-\mathrm{A} \& \mathrm{~F}$ interventions for clinical practice in primary care and hospital settings. Our objectives were to (1) assess the effect of these intervention on quality of care; (2) identify common aspects of the 
TDF employed as mechanisms of behaviour change in these intervention, and (3) explore links between identified TDF aspects, their nature or pattern of use across interventions and the magnitude of their effect size.

\section{Methods}

We followed the Preferred Reporting Items for Systematic Reviews and Meta-Analyses (PRISMA) [28] statement for reporting our systematic review. PRISMA gives an evidence-based minimum set of recommendations for the reporting of systematic reviews and meta-analyses evaluating randomised trials, and can also be used as a basis for reporting systematic reviews of other types of research, e.g. evaluations of interventions [28].

\section{Criteria for considering studies for this review Types of studies}

Studies that assessed audit and feedback using randomised controlled trials (RCTs) were eligible for inclusion.

\section{Types of participants}

Studies involving feedback recipients who were healthcare professionals responsible for patient care were eligible for inclusion.

\section{Types of intervention}

Provider-oriented e-A\&F interventions, defined as A\&F interventions that utilised computer interfaces to provide clinical performance summaries to healthcare professionals, that specifically targeted behaviour change as part of clinical practice improvement were considered.

\section{Types of outcome measures}

Processes of care:

1. Dichotomous process measures. Percentage of patients receiving a target process of care (e.g. prescription of a specific medication, documentation of performance of a specific clinical task) or whose care was in compliance with overall clinical guidelines.

2. Continuous process measures. Any continuous measure of how providers delivered care (e.g. duration of antibiotic therapy, time to respond to a critical lab value).

Outcomes of care

3. Dichotomous clinical outcomes. True clinical endpoints (e.g. mortality and development of a pulmonary embolism), as well as proxy endpoints, e.g. achievement of a target blood pressure or blood glucose level.

4. Continuous clinical outcomes. Various markers of disease or health status (e.g. mean blood pressure or cholesterol level).

\section{Exclusion criteria}

Studies whose focus was solely on non-clinical indicators (e.g. indicators on costs, financing, workload, coverage and time management), patient-reported experience measures, those that did not include an e-A\&F arm component in case of a multi-faceted intervention and those that only reported feedback to patients were excluded. Non-electronic A\&F, e.g. those delivering feedback verbally, by paper, telephone calls and electronic non-interactive A\&F (i.e. they do not offer a computer interface which allows users to filter, drill down and further explore their performance summaries), e.g. emailed feedback were also excluded, as were studies that were not peer-reviewed or published in English.

\section{Data collection and analysis Data sources and search strategy}

We identified all relevant studies through a two-step search approach. An initial search strategy was developed based on MEDLINE indexed, informed by and including studies from the most recent Cochrane systematic review on $A \& F$ [2]. It was translated into the other databases using the appropriate controlled vocabulary as applicable (see Additional file 2 for the complete search strings and results). Reference lists of all included studies were also reviewed. We searched the following databases:

- MEDLINE and Ovid (1946 to August week 3 2016) - searched 12 August 2016

- EMBASE and Ovid (1974 to 2016 week 35)-searched 12 August 2016

- Cochrane Central Register of Controlled Trials (CENTRAL) 2016, Issue 8, part of The Cochrane Library. http://www.thecochranelibrary.com/, including the Cochrane Effective Practice and Organisation of Care (EPOC) Group Specialised Register-searched 12 August 2016

- CINAHL and EBSCOhost (1981 to present) searched 12 August 2016

- Science Citation Index and Social Sciences Citation Index, ISI Web of Science (1975 to present)-searched 12 August 2016

Search terms for electronic aspect of A\&F were identified from running Ivers et al. search string [2], identifying Medical Subject Heading (MeSH) and common free-text terms used in studies with e-A\&F. Through an iterative process, additional search terms from studies meeting our inclusion criteria were identified and used to strengthen the electronic filter.

\section{Selection of studies}

Two authors (TT and SV) independently screened the titles and abstracts against the inclusion criteria to 
identify potentially relevant studies. Where there was uncertainty, complete manuscripts were sought and disagreements were resolved through discussion. Full manuscripts underwent the same screening process by the same authors (TT and SV).

\section{Data extraction and management}

Data were extracted using a tailored version of EPOC's data abstraction tool [29] by one reviewer (TT) and were checked by a second reviewer (MN); disagreements were resolved by discussion. Data extraction was guided by the EPOC data collection checklist [29], which we complemented with modifiable design elements of e-A\&F suggested in previous systematic reviews $[2,28,30]$. We extracted data on: study design; study participants (e.g. cadre, team setup and clinical context); feedback characteristics (e.g. frequency of updates, interactive elements of the intervention, feedback content and reported benchmarks); intervention goals (baseline comparisons, direction of change, explicit action goal, etc.); reported effect size of primary outcomes only.

Two reviewers (TT and MN) independently assessed the risk of bias using Cochrane's Review Manager software (V5.3) [31]. This included risk of selection bias (random sequence generation, allocation concealment and selection of two groups), reporting bias (blinding) and confounding (baseline characteristics and interventions). For each criterion, the study was classified as high risk of bias, low risk of bias or unclear risk of bias. An overall assessment of the risk of bias (low, medium and high risk of bias) was assigned to each of the included studies using the approach suggested in the Cochrane Handbook for Systematic Reviews of Interventions [32]. Studies with low risk of bias for all key domains or where at least four of the six criteria had low risk of bias with the other two not being attrition or reporting bias were considered to have a low risk of bias. Studies where risk of bias in at least one domain was unclear and at most three domains had low risk of bias were considered to have an unclear risk of bias. Studies with a medium risk of bias had three domains with low risk of bias that did not include attrition or reporting bias. Studies with a high risk of bias in at least four domains or random sequence generation bias, which decreased the certainty of the conclusions were considered to have a high risk of bias.

\section{Identifying TDF domains}

Two reviewers (TT, JN-a social scientist) independently extracted verbatim statements from the papers that referred to TDF domains that appeared to be targeted in the intervention and control arms, either explicitly or implicitly. These verbatim statements were summarised into TDF domains based on reported intervention elements and characteristics. The coding into domains was supported by evidence from the text, and inferences were made about which domains the authors intended to target in case this was not stated explicitly in the text. This was achieved by studying the descriptions of the interventions; each aspect judged to be targeting a domain with respect to the behaviours of clinician was coded (e.g. if social comparisons were used within e-A\&F to evaluate clinician's attitudes, abilities or performance relative to others, TDF's domain 'social influences' was inferred to have been target etc.). The 12 theoretical domains from TDF [23] informed coding and selection of relevant domains (see Additional file 3). Discrepancies in statement extraction and coding were resolved by discussion. For one study, a third reviewer (BB) independently extracted statements and coded them to verify the sturdiness of the coding process.

\section{Data synthesis}

Using the identified TDF domains, we analysed the commonly targeted aspects of TDF by looking at the frequency with which domains had been targeted in the studies. We also explored the nature and pattern of TDF domain use across the different studies and the associated magnitude of effect size. The reference table with the TDF domains and explanations that guided coding decisions is provided in Additional file 3. We descriptively reported the TDF aspects and primary outcomes' effect sizes at the study-level, counting the number of times a domain had been identified across studies, and a descriptive analysis of potential links. We reported odds ratio reflecting adherence to desired practice from the primary dichotomous study outcomes.

For the quantitative meta-analysis, we assessed heterogeneity across studies to determine whether pooling of effect sizes was possible. Across studies, the effect size was weighted by the number of health professionals involved in the study reported to ensure that small studies did not contribute the same to the overall estimate as larger studies. Where the number of health professionals was not reported, the number of practices/hospitals was used instead. The summary statistics in the meta-analyses are reported as weighted odds ratio or weighted change relative to baseline control, weighted by the number of health professionals. This was supplemented by random effects univariate linear regression analysis used to explore potential sources of heterogeneity (e.g. intervention duration, feedback recipients, feedback frequency, feedback formats and theoretical domains targeted).

\section{Results}

Our electronic searches yielded 715 unique papers, of which 33 were screened based on full text. Twenty-four papers were excluded after full review, and we included 
nine publications reporting the findings of seven studies (see Fig. 1).

\section{Description of studies and e-A\&F interventions}

Table 1 describes the characteristics of included studies and the e-A\&F interventions they evaluated. Study settings varied, but all were from developed countries, with three studies conducted in very specialised settings, i.e. ancillary [33] and specialised cardiovascular units $[34,35]$ respectively. Only three out of the seven studies targeted interdisciplinary clinical teams [34-36].

Benchmarks provided in the e-A\&F reports most commonly offered comparisons of individual performance versus average local and national performance [33, 34, 37-39], or local site performance versus performance of all participating study sites [36, 40,41]. Our definition of benchmarks is defined in detail elsewhere [42]. If there were other quality improvement (QI) strategies used, we assessed the extent to which one would reasonably consider $\mathrm{e}-\mathrm{A} \& \mathrm{~F}$ to be the key intervention to which the effect size would be attributed. Three categories identified were: (1) whether e-A\&F was optional (minimal), (2) whether e-A\&F was mandatory but included other QI interventions most of which were not implemented within e-A\&F (moderate), (3) whether e-A\&F was mandatory and included other QI interventions most of which were implemented within e-A\&F (core).

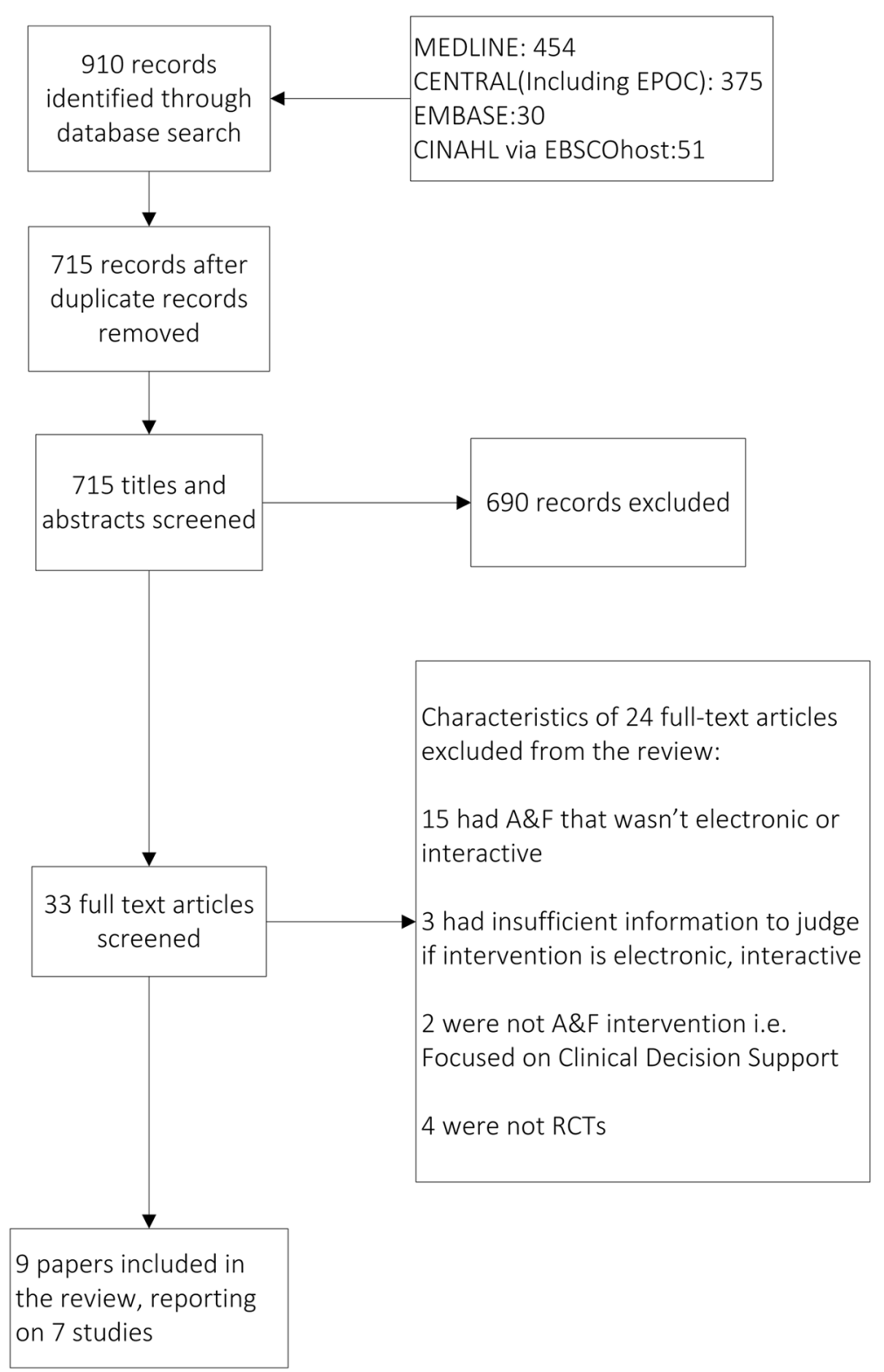

Fig. 1 Flow diagram detailing process of including studies into the review 


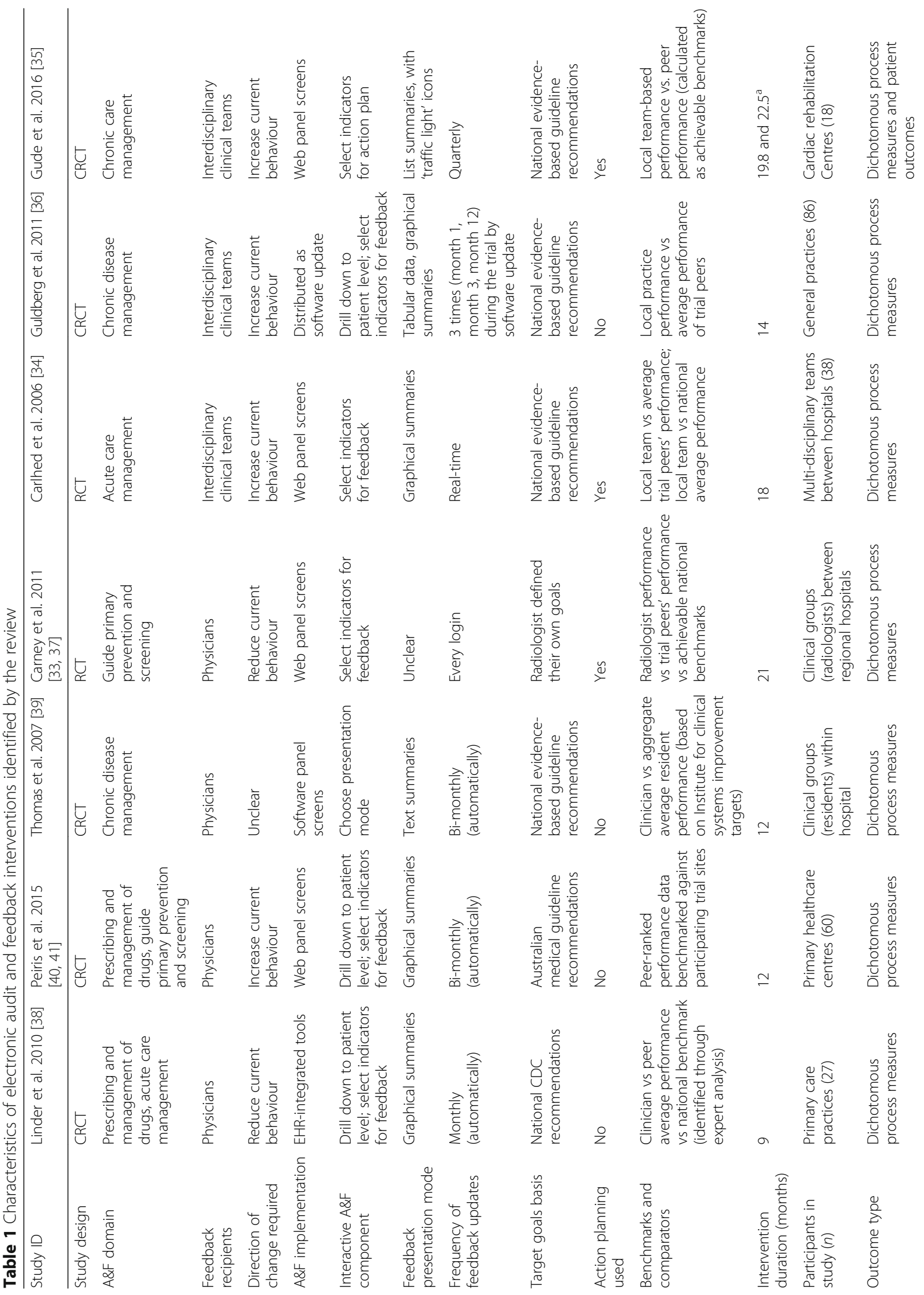




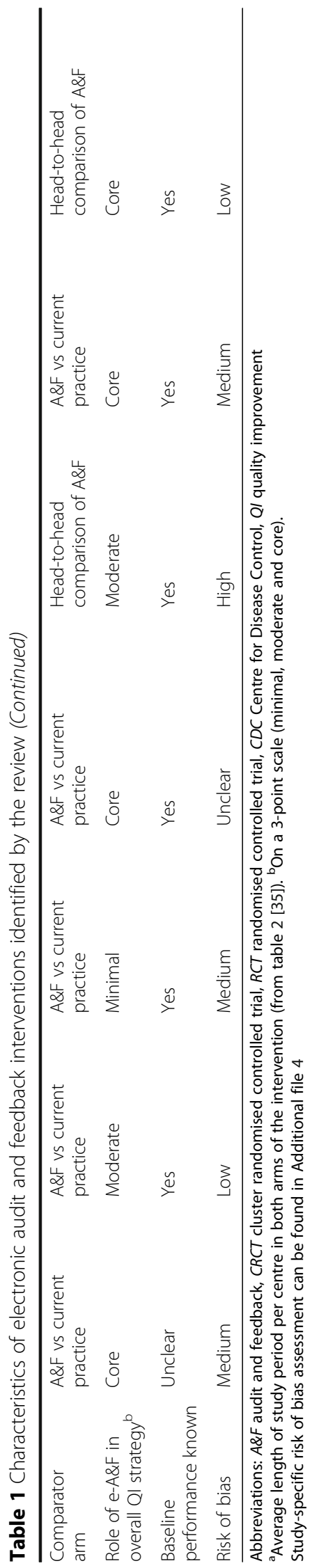


In two studies, the intervention allowed clinicians to set their own goals or actions and track them [34, 35], with the rest utilising guidelines from professional bodies and/ or evidence from previous studies as the study goals.

With regard to their interactive characteristics, six eA\&F interventions allowed recipients to select which additional indicators to include in their feedback report, in three cases feedback recipients, could drill down to specific patient population details [36, 38, 40, 41]. The implementation of the e-A\&F interventions varied in design and form. Four studies created web panels containing patient data to be used for A\&F, with one using stand-alone software program [39], and another one implementing an integrated EHR tool [38]. One study combined the electronic performance data with a software program that rendered it digitally and distributed these 'updates' regularly [36]. Interventions that had not been integrated in electronic health records had a separate process of data collation, with data being queried from medical records to populate a separate e-A\&F tool.

In describing the control arm of the study, only three studies went beyond stating usual care and gave a clear detailed description of what the intervention was being tested against [34, 35, 39]. None of the studies randomised feedback design elements within intervention arms, but one did compare outcomes within the intervention arm based on rate of use of e-A\&F [38]. Of the seven studies included, studies with the highest number of participants $[35,41]$ had a low risk of bias; three had a high risk [34, 36, 38] (see Fig. 2). The most common sources of a high risk of bias related to blinding of participant and personnel selection bias; clarity of reporting regarding the risk of bias was often insufficient (see Additional file 4 for a summary of risk of bias assessments across studies).

\section{Effect of e-A\&F interventions on quality of care}

Table 2 displays the effect size and associated 95\% confidence interval $(95 \% \mathrm{CI})$ for each included study. Three studies found a positive effect of the e-A\&F intervention on the quality of care. Peiris et al. reported a statistically significant difference of $9.4 \%$ (OR 1.47, 95\% CI 1.411.53) between the intervention and control group for the number of patients who received appropriate screening of cardiovascular risk [40, 41]. Thomas et al. reported a statistically significant difference of 13\% (OR 1.72, 95\% CI 1.20-2.47) and 11.7\% (OR 1.75, 95\% CI 1.18-2.59) between the intervention and control group for patients who received appropriate haemoglobin and cholesterol testing, respectively [39]. Carlhed et al. reported statistically significant difference of $10.6-14.9 \%$ between the intervention and control group in four out of five Swedish national guideline-derived quality indicators of acute myocardial infarction [34]. None of the other studies found an effect of the intervention on all the outcome measures evaluated.

The weighted odds ratios of each primary outcome for each study and all studies combined for e-A\&F are shown in Fig. 3, with substantial heterogeneity observed across studies $\left(P_{\text {heterogeneity }}<0.001, I^{2}=99.12 \%, 95 \%\right.$ CI: 98.25-99.68). The weighted odds ratio of compliance with desired practice was 1.93 (95\% CI: 1.36-2.73) when considering e-A\&F to no A\&F. Please note that due to the high variation as illustrated by $I^{2}$ value, this average effect should not be considered reliable. We could not reduce the heterogeneity by considering subsets of outcome measures. The summary odds ratio of e-A\&F comparing the intervention arm with access to e-A\&F to control arm without the same access was highly unreliable due to high heterogeneity. Carney et al. was omitted from meta-analysis due to missing information in their report, i.e. they did not include the number of screening mammograms with a recommendation for immediate follow-up (a positive result) for both intervention and control arms of the study at intervals 1 and 2 [33, 37]. In Gude et al. [35], both arms of the study received e-A\&F (but for different sets of outcomes, and so were each other's control). Given the evidence of contamination effect that $A \& F$ might have on overall quality of care in general even if a subset of indicators are being tracked (Susan Gachau, et al., Effects of audit and feedback delivered within an emerging clinical network in Kenya on multiple

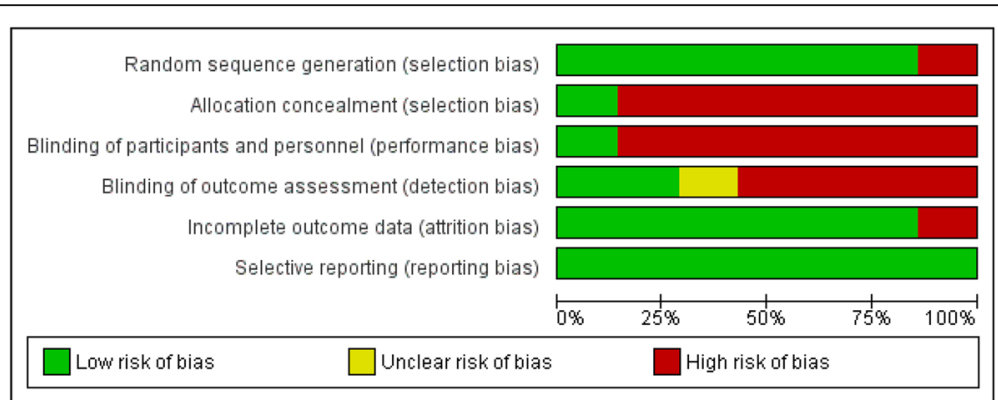

Fig. 2 Risk of bias graph. Review authors' judgements about each risk of bias item presented as percentages across the seven included studies. Study specific bias assessment can be found in Additional file 3 
Table 2 Primary outcomes of the identified studies and the reported effect size

\begin{tabular}{|c|c|c|c|}
\hline Study ID & $\begin{array}{l}\text { Intervention sample size; } \\
\text { control sample size }\end{array}$ & Outcome of interest & Odds ratio $(95 \% \mathrm{Cl})$ \\
\hline Linder et al. 2010 [38] & $\begin{array}{l}\text { I: } 258 \text { clinicians; } \\
\text { C: } 315 \text { clinicians }\end{array}$ & (1) Antibiotic prescribing rate for acute respiratory infection & $0.97(0.92-1.03)$ \\
\hline \multirow[t]{2}{*}{ Peiris et al. 2015 [41] } & $\begin{array}{l}\text { I: } 19385 \text { patients; } \\
\text { C: } 19340 \text { patients }\end{array}$ & $\begin{array}{l}\text { (1) Patients who received appropriate screening of cardiovascular } \\
\text { risk factors by the end of study }\end{array}$ & $1.47(1.41-1.53)$ \\
\hline & $\begin{array}{l}\text { I: } 5335 \text { patients; } \\
\text { C: } 4846 \text { patients }\end{array}$ & (2) Prescription rate of recommended medications for high-risk cohort & $1.25(1.16-1.35)$ \\
\hline \multirow[t]{2}{*}{ Thomas et al. 2007 [39] } & \multirow[t]{2}{*}{$\begin{array}{l}\text { I: } 252 \text { patients; } \\
\text { C: } 231 \text { patients }\end{array}$} & $\begin{array}{l}\text { (1) Diabetes care metrics for all participating residents' patients at } \\
\text { study inception and completion including haemoglobin } \\
\text { monitoring in the prior } 6 \text { months }\end{array}$ & $1.72(1.20-2.47)$ \\
\hline & & $\begin{array}{l}\text { (2) Diabetes care metrics for all participating residents' patients } \\
\text { at study inception and completion lipid monitoring in the } \\
\text { prior } 12 \text { months }\end{array}$ & $1.75(1.18-2.59)$ \\
\hline \multirow[t]{5}{*}{ Carlhed et al. 2006 [34] } & \multirow{5}{*}{$\begin{array}{l}\text { I: } 3786 \text { patients; } \\
\text { C: } 2940 \text { patients }\end{array}$} & (1) Lipid-lowering therapy at discharge & $3.26(2.49-4.27)$ \\
\hline & & (2) Angiotensin-converting enzyme (ACE) inhibitors at discharge & $10.08(7.31-13.90)$ \\
\hline & & (3) Clopidogrel at discharge & $1.96(1.77-2.18)$ \\
\hline & & (4) Heparin or low-molecular weight heparin (LMWH) during hospitalisation & $3.47(2.89-4.16)$ \\
\hline & & $\begin{array}{l}\text { (5) Performed coronary angiography (or, for hospitals lacking in-house } \\
\text { coronary angiography, referral to another hospital) }\end{array}$ & $3.05(2.57-3.63)$ \\
\hline \multirow[t]{4}{*}{ Guldberg et al. 2011 [36] } & $\begin{array}{l}\text { I: } 1196 \text { patients; } \\
\text { C: } 1050 \text { patients }\end{array}$ & (1) Haemoglobin measurement sustained & $0.86(0.59-1.25)$ \\
\hline & $\begin{array}{l}\text { I: } 121 \text { patients; } \\
\text { C: } 91 \text { patients }\end{array}$ & (2) Haemoglobin measurement initiated if no measurement at baseline & $0.77(0.45-1.33)$ \\
\hline & $\begin{array}{l}\text { I: } 1109 \text { patients; } \\
\text { C: } 887 \text { patients }\end{array}$ & (3) Cholesterol measurement sustained & $1.74(1.35-2.24)$ \\
\hline & $\begin{array}{l}\text { I: } 208 \text { patients; } \\
\text { C: } 258 \text { patients }\end{array}$ & (4) Cholesterol measurement initiated if no measurement at baseline & $2.07(1.38-3.12)$ \\
\hline \multirow[t]{2}{*}{ Carney et al. 2011 [33] } & \multirow{2}{*}{$\begin{array}{l}\text { I: } 23 \text { radiologists: } \\
\text { C: } 9 \text { radiologists }\end{array}$} & (1) Mean recall rates at time $\mathrm{T1}$ (0-9 months) & $1.12(1.00-1.27)$ \\
\hline & & (2) Mean recall rates at time T2(9-18 months) & $1.10(0.96-1.25)$ \\
\hline \multirow[t]{12}{*}{ Gude et al. 2016 [35] } & $\begin{array}{l}\text { l: } 7341 \text { patients; } \\
\text { C: } 4591 \text { patients }\end{array}$ & (1) Complete data on psychological functioning & $1.07(0.46-2.5)$ \\
\hline & $\begin{array}{l}\text { l: } 7341 \text { patients; } \\
\text { C: } 4591 \text { patients }\end{array}$ & (2) Complete data on social functioning & $7.95(0.54-116.3)$ \\
\hline & $\begin{array}{l}\text { I: } 7341 \text { patients; } \\
\text { C: } 4591 \text { patients }\end{array}$ & (3) Complete data on lifestyle factors & $1.11(0.45-2.75)$ \\
\hline & $\begin{array}{l}\text { l: } 4934 \text { patients; } \\
\text { C: } 4071 \text { patients }\end{array}$ & (4) Disease specific education completed ${ }^{a}$ & $0.57(0.31-1.06)$ \\
\hline & $\begin{array}{l}\text { I: } 5580 \text { patients; } \\
\text { C: } 4591 \text { patients }\end{array}$ & (5) Lifestyle modification programme completed ${ }^{a}$ & $1(0.48-2.04)$ \\
\hline & $\begin{array}{l}\text { l: } 4591 \text { patients; } \\
\text { C: } 7341 \text { patients }\end{array}$ & (6) Improved quality of live after $C R$ & $0.99(0.84-1.19)$ \\
\hline & $\begin{array}{l}\text { I: } 7341 \text { patients; } \\
\text { C: } 4591 \text { patients }\end{array}$ & (7) Successful smoking cessation & $1.02(0.86-1.2)$ \\
\hline & $\begin{array}{l}\text { I: } 7341 \text { patients; } \\
\text { C: } 4591 \text { patients }\end{array}$ & (8) Patients receive a discharge letter with remaining lifestyle goals & $0.87(0.27-2.81)$ \\
\hline & $\begin{array}{l}\text { I: } 4591 \text { patients; } \\
\text { C: } 7341 \text { patients }\end{array}$ & (9) Complete data on physical functioning & $1.32(0.45-3.84)$ \\
\hline & $\begin{array}{l}\text { I: } 4591 \text { patients; } \\
\text { C: } 7341 \text { patients }\end{array}$ & (10) Complete data concerning cardiovascular risk factors & $1.2(0.65-2.23)$ \\
\hline & $\begin{array}{l}\text { I: } 2922 \text { patients; } \\
\text { C: } 7341 \text { patients }\end{array}$ & (11) Exercise training completed ${ }^{a}$ & $1.64(0.57-4.71)$ \\
\hline & $\begin{array}{l}\text { I: } 4071 \text { patients; } \\
\text { C: } 4898 \text { patients }\end{array}$ & (12) Relaxation and stress management training completed ${ }^{\mathrm{a}}$ & $0.44(0.14-1.41)$ \\
\hline
\end{tabular}


Table 2 Primary outcomes of the identified studies and the reported effect size (Continued)

$\begin{array}{lll}\text { I: } 4591 \text { patients; } & \text { (13) Cardiovascular risk factors evaluated at discharge } & 1.22(0.4-3.76) \\ \text { C: } 7341 \text { patients } & & 0.86(0.69-1.07) \\ \text { I: } 4591 \text { patients; } & \text { (14) Improvement in exercise capacity } & 1.04(0.86-1.24) \\ \text { C: } 7341 \text { patients } & \text { (15) Successful work resumption } & 1.03(0.82-1.29) \\ \text { I: } 4591 \text { patients; } & & \\ \text { C: } 7341 \text { patients } & \text { (16) Moderately active lifestyle norm met at discharge } \\ \text { I: } 4591 \text { patients; } & \text { (17) Vigorously active lifestyle norm met at discharge } & 0.88(0.74-1.04) \\ \text { C: } 7341 \text { patients } & & \end{array}$

Note: I intervention arm, C control arm. ${ }^{a}$ Excluded centres with incomplete data for this outcome

indicators of the process of paediatric hospital care - a longitudinal observational study. BMJ Quality and Safety, submitted), and the admission in this study's report of risk of contamination, it was omitted from the meta-analysis.

Further exploration of possible sources of heterogeneity as detailed in previous reviews [2] showed the number of theoretical domains targeted in the control arm, feedback characteristics (graphical feedback, A\&F headto-head comparison and real-time feedback frequency) and intervention duration to be the biggest explicators of the level of heterogeneity (Table 3). The components of the meta-regression reported in Table 3 were tested univariately, i.e. each separately from one another. A multivariable meta-regression model adjusting for effects of all components on intervention effect was not possible due to the small number of studies $(n=5)$ and outcomes $(n=14)$ included in the meta-analysis.

\section{Common aspects of TDF employed as change behaviour mechanisms in e-A\&F}

Only two studies explicitly reported using theory (adult learning theory and control theory) to inform intervention design and reported to have tested theoretical concepts with the trial $[33,35]$. The coding for the domains targeted in the intervention and control groups for each of the studies is shown in Table 4 below. The reference table with the TDF domains and explanations that guided coding decisions is provided in Additional file 3.

Table 5 presents the number of times each of the domains were coded for both arms in each included study. For five studies, we identified at least six domains identified in the intervention arm [33-35, 37, 39-41]. The study informed by adult learning theory had the most domains identified in the intervention arm, but did not describe its control arm with the same rigour [33].

The most frequently coded domains in the intervention arm were 'knowledge,' 'motivation and goals' and 'social influences' (all seven studies). The knowledge domain was also coded for the two studies that included a description of the intervention in the control arm [34, 39]. The most commonly coded domains when intervention and control arm of trials were combined were knowledge (coded ten times) and motivation and goals and social influences (both coded nine times). We did not identify any studies whose interventions targeted 'social/professional role and identity' or 'emotion'.

Of the three studies that found a positive effect of the eA\&F intervention on the quality of care, one had the second highest number of coded domains in intervention arm $[40,41]$, and the other two were the only studies with domains coded in both intervention and the control arm $[34,39]$. The low number of studies identified did not allow any inferences about patterns of theoretical domains identified and their link with effect sizes.

\section{Discussion}

\section{Summary of findings}

Our meta-analysis of five studies revealed the included electronic audit and feedback (e-A\&F) interventions to be highly heterogeneous, even when subsets of outcome measures were considered. The weighted pooled odds ratio of compliance with desired practice was 1.93 (95\% CI 1.36-2.73) when considering e-A\&F to no A\&F. This pooled average effect suffered from distortion as studies had varied sizes, differed in results and tended to be biased. Additionally, the meta-regression results would likely be biased given that they tend to have poor performance where there are few studies [43]. We therefore considered this average effect to be unreliable. Using the theoretical domains framework (TDF) to identify the theoretical concepts underlying the interventions, we found that the TDF domains of knowledge, motivation and goals and 'social influences' were most commonly targeted; professional identity and emotion were not targeted by any of the interventions. Due to the small number of studies identified, inferences about patterns of domains and their link with effect sizes could not be made.

\section{Relation to other studies}

To our knowledge, we are the first to perform a metaanalysis of the effectiveness of e-A\&F interventions. Ivers et al. [2] identified 140 randomised controlled trials 


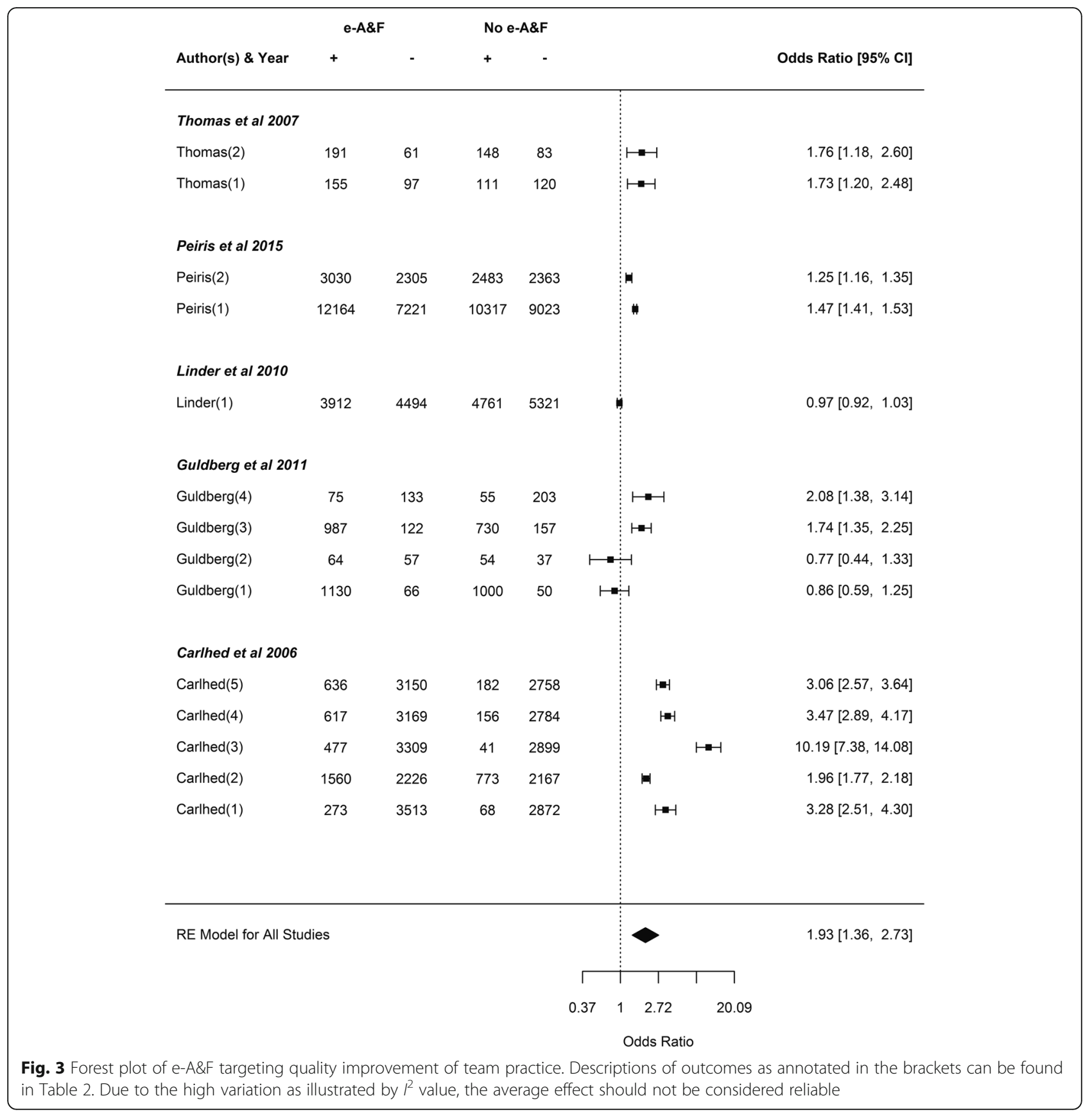

(RCTs) of A\&F interventions that objectively measured provider performance in a healthcare setting. However, whereas they included feedback in any format, we focused on A\&F interventions that were delivered electronically. Two studies included in our review $[36,39]$ were also identified by Ivers et al. Their meta-regression of studies featuring dichotomous outcomes included 82 comparisons from 49 studies. For dichotomous outcomes, Ivers et al. found the weighted median risk difference to be $4.3 \%$ increase in compliance with desired practice, unlike our results where we could not determine a reliable average effect due to high heterogeneity. This difference might partly be due to their exclusion of studies with a high risk of bias from analysis whereas we included all the studies with sufficient baseline information. Our exploration of sources of heterogeneity yielded similar findings to Ivers et al. on significance of instructions for improvement and feedback frequency for A\&F. However, the inability to make firm conclusions from the analysis of heterogeneity due to the indirect nature of the comparisons is common in both studies. Our heterogeneity findings are further compounded by the small number of identified studies. 
Table 3 Random effects meta-regression model

\begin{tabular}{llll}
\hline Covariate & $\begin{array}{l}P^{2} \text { residual heterogeneity/unaccounted } \\
\text { variability }\end{array}$ & $R^{2}$ amount of heterogeneity accounted for & $P$ value (moderator) \\
\hline Null model & $99.12 \%$ & - & - \\
Size of clinical teams & $98.97 \%$ & $\mathbf{0 . 0 0 \%}$ & 0.884 \\
Intervention duration & $98.03 \%$ & $51.70 \%$ & $0.001^{* *}$ \\
Interdisciplinary teams & $98.96 \%$ & $\mathbf{1 0 . 4 0 \%}$ & 0.142 \\
Real-time feedback & $97.81 \%$ & $58.04 \%$ & $0.001^{* *}$ \\
Graphical feedback & $99.24 \%$ & $\mathbf{0 . 0 0 \%}$ & 0.825 \\
TDF & & & 0.723 \\
No. of intervention domains coded & $98.79 \%$ & $\mathbf{0 . 0 0 \%}$ & $0.001^{* *}$ \\
No. of control domains coded & $97.65 \%$ & $60.81 \%$ & \\
\hline
\end{tabular}

Note: Model is a univariate regression. 'Result is also the same for local goals and 'A\&F head-to-head comparison.' 'Significance codes: 0 ****', $0.001^{* * * \prime,} 0.01^{~ * * \prime, ~} 0.05^{\prime}$

We identified two more intervention characteristics (number of TDF elements on control arm and intervention duration) as being possible sources of heterogeneity in $\mathrm{e}-\mathrm{A} \& \mathrm{~F}$ interventions. The electronic and interactive component of feedback-which they did not evaluate-captures key aspects of feedback possibly associated with improved effectiveness. Specifically, e-A\&F facilitates autodelivery of feedback more frequently than other formats, including offering real-time updates; offers the ability to easily track measurable practice goals and adherence to specific action plans in real-time and is customisable. Additionally, e-A\&F overcomes the pragmatic consideration of additional costs associated with providing personalised feedback more frequently, which plays into its added effectiveness.

Colquhoun et al. [15] examined the extent to which explicit theory was used in the 140 RCTs of A\&F interventions identified in Ivers et al.'s review. In contrast to our study, they limited their approach to explicit use of theory and only included $14 \%$ of trials $(n=20)$, similar to what we found with only two out of seven studies explicitly stating that theory informed the design of their intervention [33, 35]. In contrast to Colquhoun et al.'s approach of classifying theories by application field, TDF represents common psychological aspects that most theories target. Our approach broadened the scope from explicit theory use while focusing on e-A\&F. This was motivated by evidence showing e-A\&F to influence contextual effect modifiers and intervention design $[9,21]$ but at the same time providing limited insight of how they can best be aligned to provide feedback supporting clinical practice, given their increasing popularity.

There are other examples of efforts to use TDF within systematic reviews such as Little et al. [22], which examined theoretical factors that post-fracture interventions aimed at patients at risk of osteoporosis, but did not include physician-directed A\&F component. Similar to our study, they applied TDF retrospectively to explore implicit use of theoretical domains. They identified five commonly targeted domains out of the possible fourteen, with all studies targeting at least four out of the five domains identified. In line with Little et al., we found that all our studies targeted knowledge and social influences domains. While they found an inverse relationship for both number of times and number of different domains coded and the effect size, our analysis found the number of different domains coded in the control arm might be considerably associated with effect size, with the number of unique domains coded in intervention arm having no effect. However, this difference might be due to the risk of bias of studies included in review-although they did not report on risk of bias assessment. Also, the heterogeneous nature of studies in our review is possibly substantively higher than in Little's review and might also account for the differences.

\section{Theoretical concepts targeted by electronic audit and feedback}

Knowledge, motivation and goals and social influences were the most frequently coded domains. In most studies included in our analysis, national guidelines determined the desired state of practice, rather than localised action-planning and goal setting. This is consistent with other studies where investigators concluded that clinical teams lacked key knowledge about practice needed to improve behaviour [35]. At the same time, goal setting recommendations propose clinicians not to be highly motivated to achieve evidence-based population-level quality targets, but instead tend to prioritise competing organisational and clinical goals [44].

Our findings related to common theoretical domains may be indicative of the belief that inclusion of local and national peer performance comparators offered a sense of importance and urgency of outcomes for teams to work towards. This reflects how feedback linked to team roles is part of a broader transformation of any clinical team, and an acknowledgement of the behavioural unit the team represents [13]. Hysong et al. argued that there is a need to understand how changes in the individual's performance impact team outcomes, and if and how 


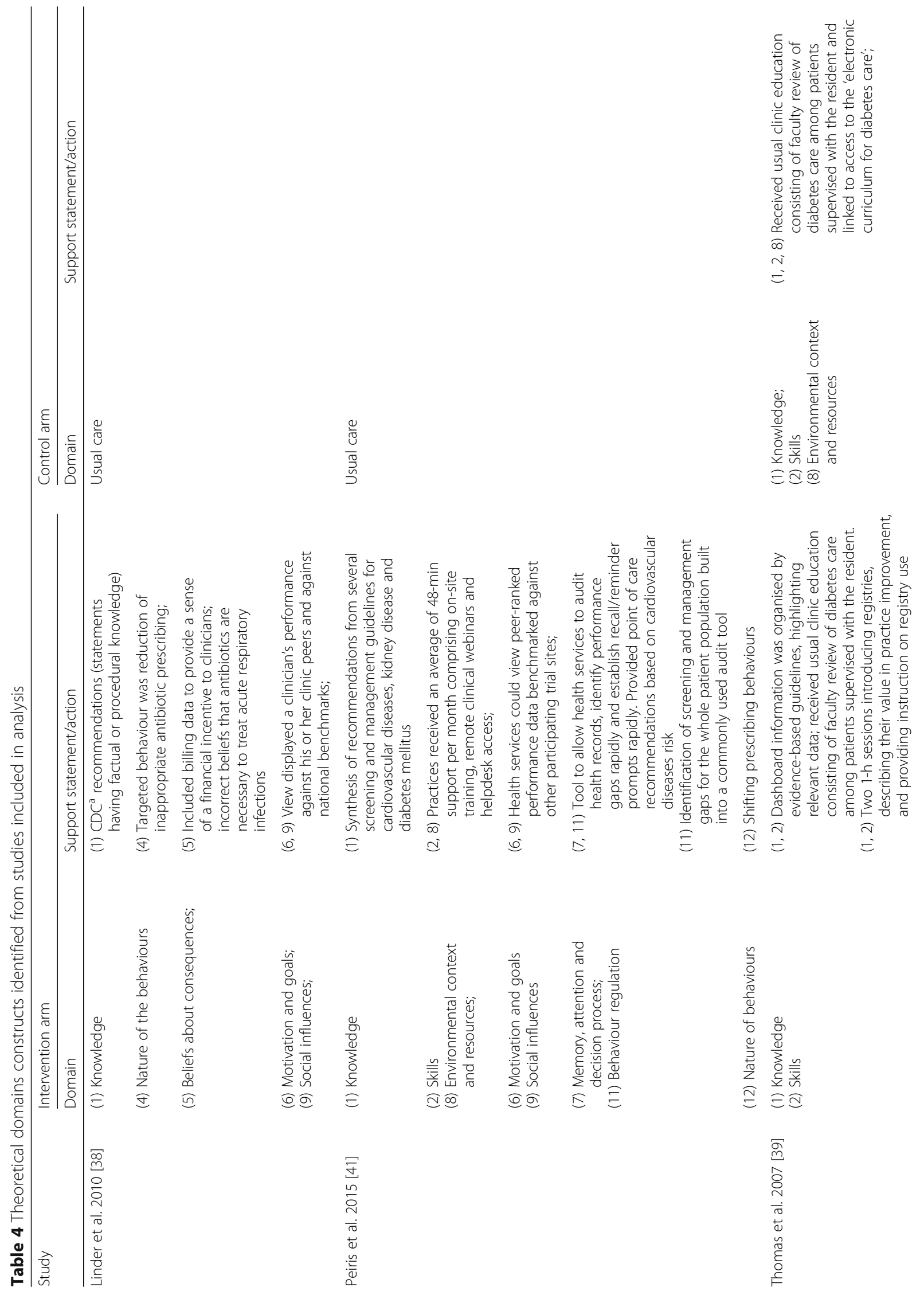




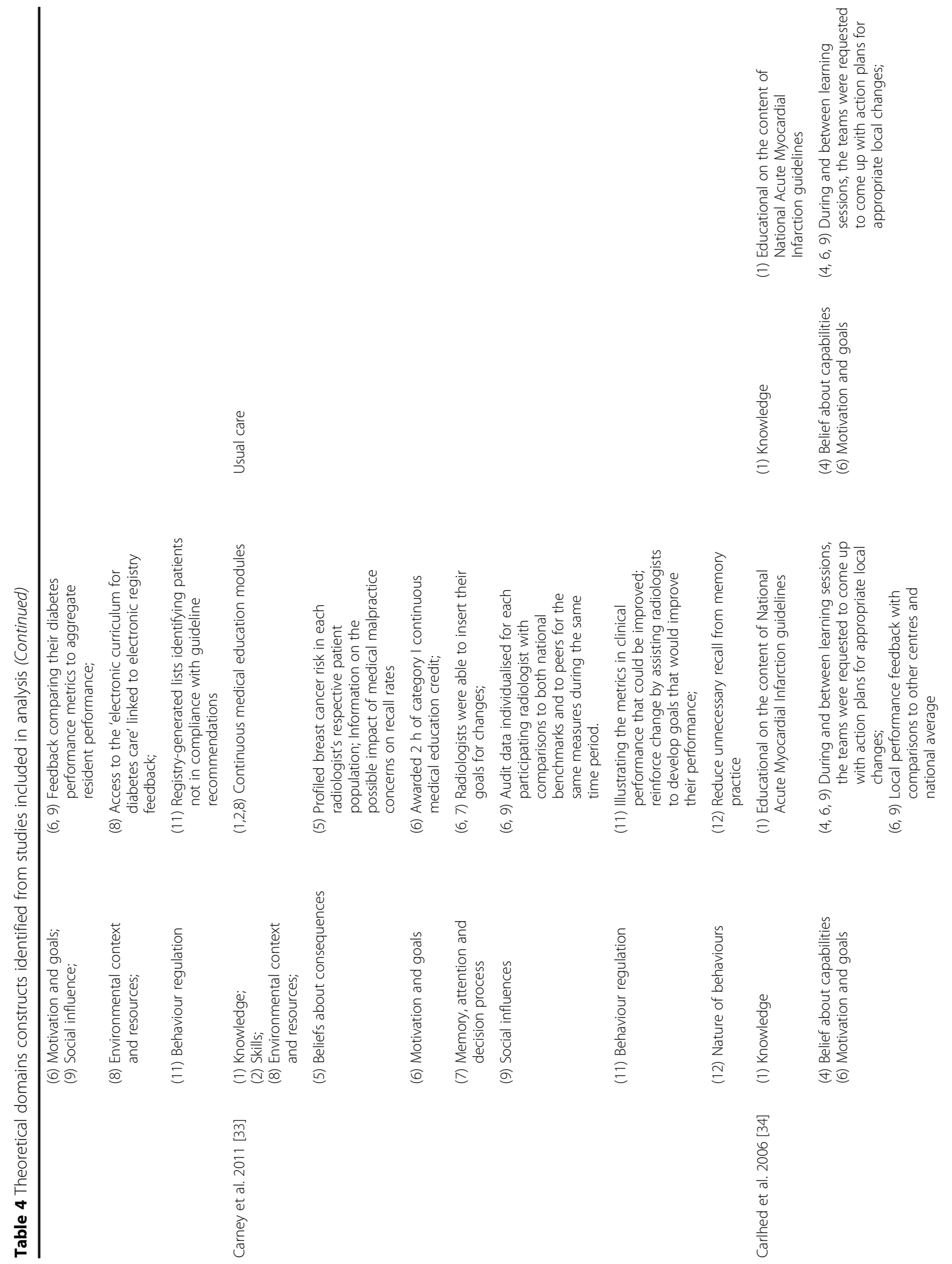




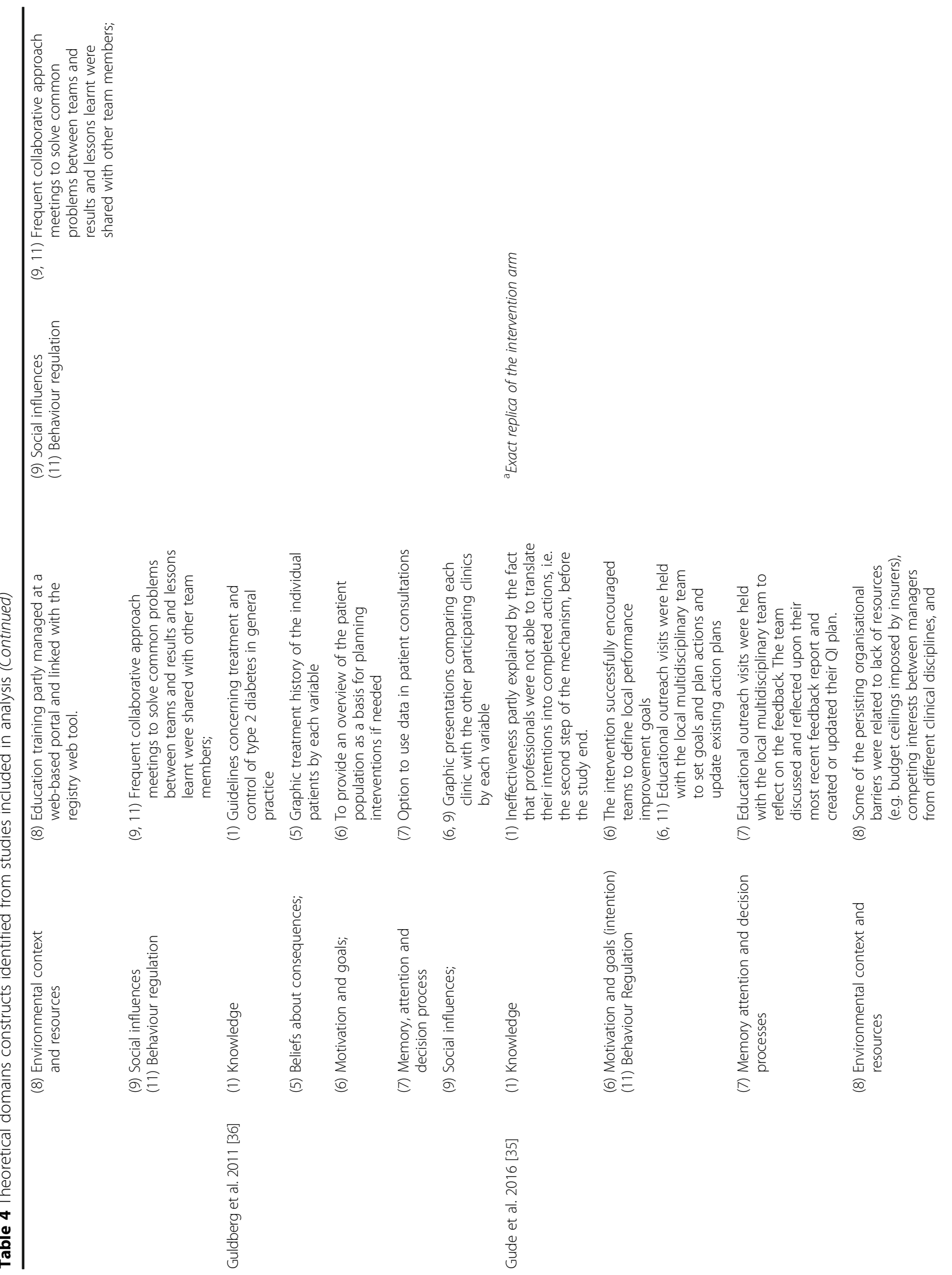




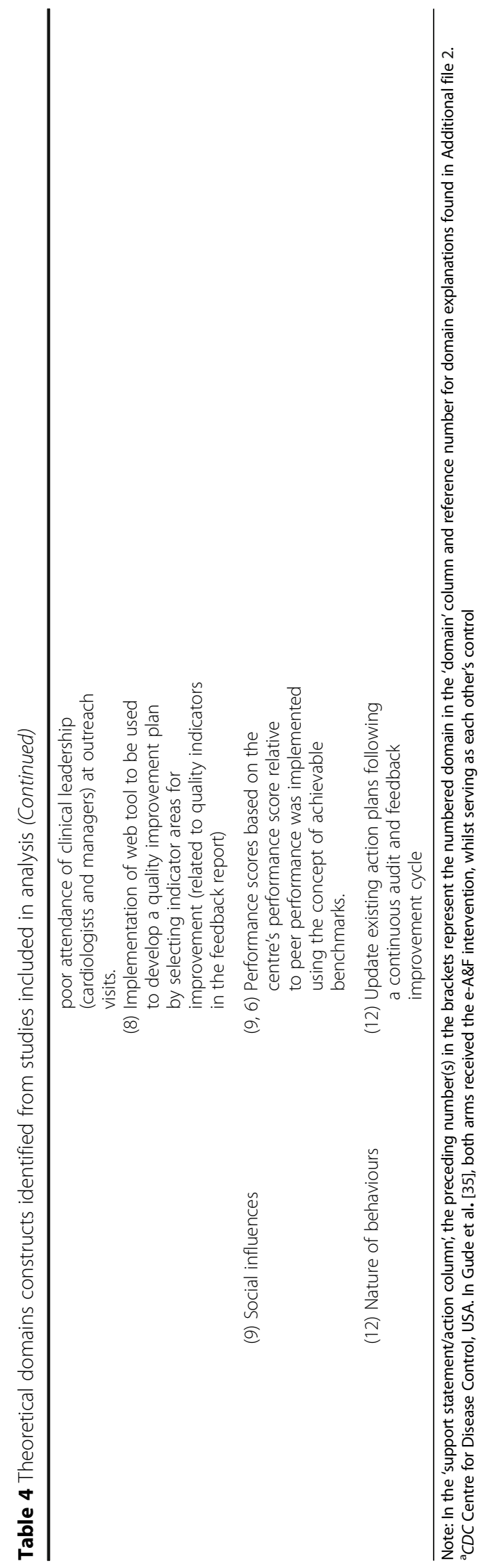




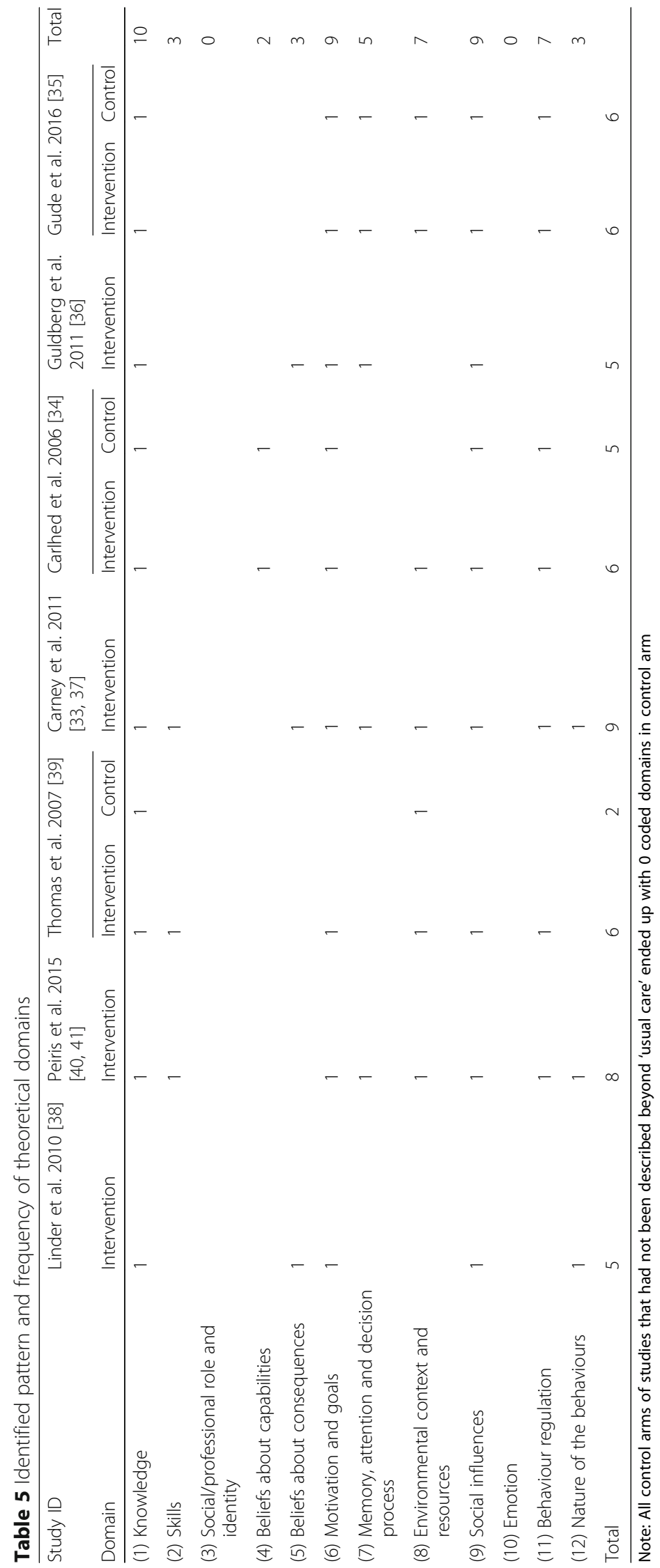


feedback practices are aligned to support teams [13]. Additionally, the studies possibly assumed that using peer ranking as social comparisons of practice behaviour would (1) instil a conscious desire among team members to maintain a certain degree of similarity in performance; and (2) help highlight a distinctive pattern of culture and practice behaviour shared by team members. One study illustrated how performance closer to benchmarks motivated change in practice [33]. This is consistent with evaluations of team practice behaviour which show improved perceptions of effectiveness and appreciable changes in practice performance where clinical teams have been regarded as a behavioural unit rather than individuals $[13,34]$. Gauging the level of interdependence, enabling efficient care coordination and encouraging parity among all individual clinicians in the quality improvement endeavour require insight into change mechanisms involved in setting a shared quality agenda [45]. However, our results do not highlight how peer ranking as a social pressure encouraged goal setting as part of regular behaviour for team members.

With regards to differences in use of theory across studies, implicit targeting of 'memory', attention and 'decision process' and 'behaviour regulation' domains represents particularly intriguing findings. Within the identified eA\&F studies targeting memory, attention and decision process, those with explicit use of theory in intervention design found no significant differences between the study arms compared to studies without explicit theory use which reported significant differences. Behavioural regulation domain, which is a fundamental pillar of how and why feedback purportedly works, could not be confidently identified from two studies [36, 38]. Where the processes of goal selection, prioritisation and monitoring, coupled with action planning were not included in the feedback process, it is difficult to ascertain the active components that had a significant effect on outcomes [9]. This might signal a tendency to overestimate the impact of theoretical domains on outcome effect where active components of A\&F are not well defined or targeted [2, 9]. It can also be indicative of how lack of adoption of a menu of theoretical domains in intervention design limits the ability to validate each domain within the context of e-A\&F [46]. However, due to the small number of studies identified, it was difficult to theorise the relationship between the differences in theoretical domains targeted across studies and their impact on the effect size.

Professional identity and emotion were rarely coded, although we presumed emotion domain would not feature in $\mathrm{e}-\mathrm{A} \& \mathrm{~F}$ interventions given the lack of evidence within digital health on how it has previously been targeted. This was indicative of how clinical team practice behaviours might have been assumed not to be influenced by these factors. Yet, these domains are posited to influence clinical practice [47-49]. Addressing this gap in future studies might further increase the understanding of effect of eA\&F interventions on practice.

\section{Implications for practice and future research}

Feedback reports delivered electronically have the potential to deliver adaptive feedback to individual team members $[13,21]$. The possibility for individual clinicians to track personal goals while still aiming to conform to group performance targets implicitly imposes expectations for future designs of e-A\&F that: (1) these interventions offer the ability to capture the intentions of team members at an individual level, and (2), they might be more informative if they cater for the evaluation of individual-team goal setting interaction. As such, future studies on $\mathrm{e}-\mathrm{A} \& \mathrm{~F}$ should aim to conduct head-to-head comparisons between individual versus team spanning: (i) goal attainment-where the feedback recipient has individual targets apart from the team's, (ii) differences in frequency of updating target goals and nature of goals pursued and (iii) differences in memory, attention and decision process as delivered by e-A\&F and in light of contextual effect modifiers.

The rationale for the interventions in our study and in some cases, how interventions were delivered was sometimes inadequately described. Descriptions of the control group specifically were often absent. This persistent problem in lack of descriptive clarity in A\&F studies [50] makes it difficult to disentangle the active ingredients of the interventions from the delivery method [9]. This curtails the ability to identify the true underlying nature of observed (lack of) behaviour changes, and it constrains the studies' replication in wider settings [2, 51, 52]. Future studies should therefore employ explicit use of theory in designing and evaluating A\&F interventions as a clear effort to improve upon understanding of A\&F mechanisms of action [9].

Additionally, testing of various theoretical concepts in a multi-component $\mathrm{e}-\mathrm{A} \& \mathrm{~F}$ interventions is now feasible through approaches such as AB testing[51]. Future e-A\&F studies ought to consider stepwise research designs, which embed tuple-wise testing of theoretical domains within audit cycles. This would allow determination of separable direct additive effects of each domain on practice behaviour. Also, varying frequency, content and delivery of feedback would help inform future intervention designs [9].

\section{Limitations}

The search strategy used to identify studies included a newly developed filter for identifying electronic interventions. As there is no consensus in definitions and terms used to describe e-A\&F, we cannot be certain that we did not miss studies based on the search terms we used. However, the rigour of the approach used for developing the electronic filter, coupled with 
an A\&F filter which has been used in a Cochrane review strengthened our search strategy [2]. We manually screened all included A\&F trials in Ivers et al's review to ensure that the search had picked up all e-A\&F studies.

Due to small numbers, we included five studies in the meta-analysis regardless of their risk of bias. As the one study with a low risk of bias was also the one with the highest weight in the analysis, we deemed a sensitivity analysis to be non-informative. However, we also examined whether differences in the level of the unit of analysis (groups of professionals/individual professionals versus patients) was a source of heterogeneity, since analyses conducted at different levels can result in different effect estimates. Overall, in hindsight, there is an argument for not doing a meta-analysis at all given the high levels of heterogeneity and the small number of studies identified. We cannot make a conclusion that electronic feedback is better than any other type of feedback, e.g. written or verbal.

\section{Conclusions}

We conclude that although opportunities for electronic $\mathrm{A} \& \mathrm{~F}$ are becoming more common, e-A\&F randomised interventions are scarce, and from our findings, highly heterogeneous. e-A\&F that have been implemented and tested in trials to support performance improvement of clinical practice tend to implicitly target only a fraction of known TDF concepts. This is further compounded by poor assessment of comparative effectiveness of targeted theoretical concepts across trial arms and high risk of bias of the studies.

This is in spite of common theoretical frameworks creating a basis for operationalization of computerised tailoring of A\&F for practice behaviour change [21]. Future research should seek to unpack the distinctions between individual and team-based electronic A\&F, including issues such as task ownership in addressing personal and team targets, behavioural distinctions in prioritising individual, team and national performance goals, and the influence of professional role, identity and intentions of team members on individual- and team-centric clinical performance goals. Research should also seek to utilise e-A\&F capabilities for evaluating of various theoretical concepts in a multi-component interventions using approaches such as $A B$ testing.

\section{Additional files}

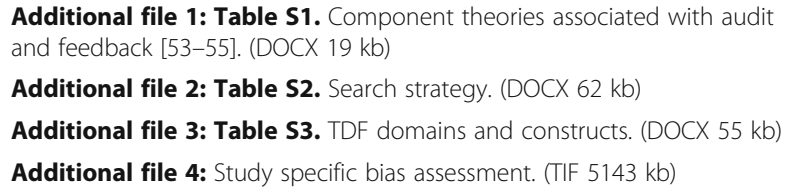

Additional file 1: Table S1. Component theories associated with audit and feedback [53-55]. (DOCX 19 kb)

Additional file 2: Table S2. Search strategy. (DOCX 62 kb)

Additional file 3: Table S3. TDF domains and constructs. (DOCX $55 \mathrm{~kb}$ ) Additional file 4: Study specific bias assessment. (TIF 5143 kb)

\section{Acknowledgements}

The authors would like to thank Dr. Zach Landis-Lewis and Mr. Wouter Gude for their help in the design of this review.

\section{Funding}

Funds from The Wellcome Trust Fellowship (\#106823) awarded to TT with additional funds from a Wellcome Trust core grant awarded to the KEMRIWellcome Trust Research Programme (\#092654) supported this work. SvdV is supported by the Health e-Research Centre (MRC Research grant MR/K006665/1). NP is supported by the NIHR Greater Manchester Primary Care Safety Translational Research Centre. ME and JN are supported by a Wellcome Trust Fellowship awarded to ME (\#097170). The funders had no role in drafting or submitting this manuscript.

\section{Availability of data and materials \\ Not applicable.}

\section{Author contributions}

$\pi T$ conceived of the study with ME. NP, BB and SV helped to design it. $\mathrm{BB}$ developed the search string for analysis and contributed to piloting abstraction tools. TT, MN and JN coded the intervention and control groups. $\Pi T$ conducted the quantitative and narrative analysis under SvdV's supervision. TT and SvdV wrote the first draft of the manuscript, and all authors commented on it and the subsequent drafts. All authors read and approved the final manuscript.

Competing interests

There are no conflicts of interest.

\section{Consent for publication}

This article was published with permission from the Director of Kenya Medical Research Institute (KEMRI)

\section{Ethics approval and consent to participate}

Not applicable.

\section{Publisher's Note}

Springer Nature remains neutral with regard to jurisdictional claims in published maps and institutional affiliations.

\section{Author details}

${ }^{1} \mathrm{KEMRI}-$ Wellcome Trust Research Programme, Nairobi, Kenya. ${ }^{2}$ Nuffield Department of Medicine, Oxford University, Oxford, UK. ${ }^{3}$ Centre for Health Informatics, Division of Informatics, Imaging and Data Sciences, Faculty of Biology, Medicine and Health, Manchester Academic Health Science Centre, The University of Manchester, Manchester, UK. ${ }^{4}$ MRC Health e-Research Centre, Farr Institute for Health Informatics Research, Manchester, UK. ${ }^{5} \mathrm{NIHR}$ Greater Manchester Primary Care Patient Safety Translational Research Centre, Manchester, UK.

Received: 3 December 2016 Accepted: 28 April 2017

Published online: 12 May 2017

\section{References}

1. Brehaut JC, Eva KW. Building theories of knowledge translation interventions: use the entire menu of constructs. Implement Sci. 2012;7(1):1.

2. Ivers $\mathrm{N}$, et al. Audit and feedback: effects on professional practice and healthcare outcomes. Cochrane Database Syst Rev. 2012;6:Cd000259.

3. Chiang, A. What is a dashboard? Digital dashboards 2011 [cited 2015 July 16th]; Available from: http://www.dashboardinsight.com/articles/digitaldashboards/fundamentals/what-is-a-dashboard.aspx.

4. Sutcliffe A, et al. Developing visualization-based decision support tools for epidemiology. Inf Vis. 2014;13(1):3-17.

5. Waitman $L R$, et al. Adopting real-time surveillance dashboards as a component of an enterprisewide medication safety strategy. Jt Comm J Qual Patient Saf. 2011;37(7):326-32.

6. National Health Service. NHS Choices. Choice in the NHS 2015 [cited 2015 June 27th]; Available from: http://www.nhs.uk/choiceintheNHS/Pages/ Choicehome.aspx.

7. Mould DR, Upton RN, Wojciechowski J. Dashboard systems: implementing pharmacometrics from bench to bedside. AAPS J. 2014;16(5):925-37. 
8. National Health Service. Clinical dashboards. Connecting for Health 2009 [cited 2015 16th July]; Available from: http://www.bsg.org.uk/pdf_word_ docs/cfh_dashboard_facts_09.pdf.

9. Ivers NM, et al. No more 'business as usual' with audit and feedback interventions: towards an agenda for a reinvigorated intervention. Implement Sci. 2014;9:14.

10. Kluger AN, DeNisi A. The effects of feedback interventions on performance: a historical review, a meta-analysis, and a preliminary feedback intervention theory. Psychol Bull. 1996;119(2):254.

11. Brehaut JC, et al. Practice feedback interventions: 15 suggestions for optimizing effectiveness. Ann Intern Med. 2016;164(6):435-41.

12. Crofts J, et al. Adaptation and implementation of local maternity dashboards in a Zimbabwean hospital to drive clinical improvement. Bull World Health Organ. 2014;92(2):146-52.

13. Hysong SJ, Knox MK, Haidet P. Examining clinical performance feedback in patient-aligned care teams. J Gen Intern Med. 2014;29 Suppl 2:S667-74.

14. Poulton BC, West MA. The determinants of effectiveness in primary health care teams. J Interprof Care. 1999;13(1):7-18.

15. Carver, C.S. and M.F. Scheier, On the self-regulation of behavior. 2001: Cambridge University Press.

16. Foy $\mathrm{R}$, et al. What do we know about how to do audit and feedback? Pitfalls in applying evidence from a systematic review. BMC Health Serv Res. 2005;5:50

17. Noar SM, Zimmerman RS. Health behavior theory and cumulative knowledge regarding health behaviors: are we moving in the right direction? Health Educ Res. 2005;20(3):275-90.

18. Colquhoun $\mathrm{HL}$, et al. A systematic review of the use of theory in randomized controlled trials of audit and feedback. Implement Sci. 2013;8:66.

19. Grol R, Wensing M. What drives change? Barriers to and incentives for achieving evidence-based practice. Med J Aust. 2004;180(6):S57.

20. Grol $R$, Wensing $M$, Eccles M, Davis D. Improving patient care: the implementation of change in health care. John Wiley \& Sons; 2013.

21. Landis-Lewis Z, et al. Computer-supported feedback message tailoring: theory-informed adaptation of clinical audit and feedback for learning and behavior change. Implement Sci. 2015;10(1):1-12.

22. Little EA, Presseau J, Eccles MP. Understanding effects in reviews of implementation interventions using the Theoretical Domains Framework. Implementation Sci. 2015:10:90.

23. Michie $\mathrm{S}$, et al. Making psychological theory useful for implementing evidence based practice: a consensus approach. Qual Saf Health Care. 2005; 14(1):26-33.

24. Murray E, et al. Normalisation process theory: a framework for developing, evaluating and implementing complex interventions. BMC Med. 2010;8(1):63.

25. May CR, et al. Evaluating complex interventions and health technologies using normalization process theory: development of a simplified approach and web-enabled toolkit. BMC Health Serv Res. 2011;11(1):245.

26. Ajzen I. Theory of planned behavior. Handb Theor Soc Psychol Vol One. 2011;1(2011):438.

27. Carver CS, Scheier MF. Control theory: a useful conceptual framework for personality-social, clinical, and health psychology. Psychol Bull. 1982;92(1):111.

28. Colquhoun, $\mathrm{H}_{\text {., }}$ et al., Reporting and design elements of audit and feedback interventions: a secondary review. BMJ Qual Saf, 2016.

29. Effective Practice and Organisation of Care (EPOC). EPOC resources for review authors. Oslo: Norwegian Knowledge Centre for the Health Services; 2015 [cited 2015 July 27th]; Available from: http://epoc.cochrane.org/epocspecific-resources-review-authors

30. Nasser, M., et al. Local consensus processes: effects on professional practice and health care outcomes. Cochrane Database of Systematic Reviews, 2007. DOI: 10.1002/14651858.CD003165.pub3.

31. The Cochrane Collaboration. Review Manager (RevMan). Copenhagen: The Nordic Cochrane Centre; 2014.

32. Higgins JP, Green S. Cochrane handbook for systematic reviews of interventions (Vol. 4). John Wiley \& Sons; 2011.

33. Carney PA, et al. Using a tailored web-based intervention to set goals to reduce unnecessary recall. Acad Radiol. 2011;18(4):495-503.

34. Carlhed R, et al. Improved adherence to Swedish national guidelines for acute myocardial infarction: the quality improvement in coronary care (QUICC) study. Am Heart J. 2006;152(6):1175-81.

35. Gude WT, et al. Effect of a web-based audit and feedback intervention with outreach visits on the clinical performance of multidisciplinary teams: a cluster-randomized trial in cardiac rehabilitation. Implement Sci. 2016;11(1):160.

36. Guldberg TL, et al. Improved quality of type 2 diabetes care following electronic feedback of treatment status to general practitioners: a cluster randomized controlled trial. Diabet Med. 2011;28(3):325-32.

37. Carney PA, et al. Impact of an educational intervention designed to reduce unnecessary recall during screening mammography. Acad Radiol. 2012; 19(9):1114-20.

38. Linder JA, et al. Electronic health record feedback to improve antibiotic prescribing for acute respiratory infections. Am J Manag Care. 2010;16(12 Suppl HIT):e311-9.

39. Thomas KG, et al. Use of a registry-generated audit, feedback, and patient reminder intervention in an internal medicine resident clinic-a randomized trial. J Gen Intern Med. 2007;22(12):1740-4.

40. Peiris $D$, et al. The treatment of cardiovascular risk in primary care using electronic decision support (TORPEDO) study: intervention development and protocol for a cluster randomised, controlled trial of an electronic decision support and quality improvement intervention in Australian primary healthcare. BMJ Open. 2012;2(6):e002177.

41. Peiris $D$, et al. Effect of a computer-guided, quality improvement program for cardiovascular disease risk management in primary health care: the treatment of cardiovascular risk using electronic decision support clusterrandomized trial. Circ Cardiovasc Qual Outcomes. 2015;8(1):87-95.

42. Agency for Healthcare Research and Quality. Module 7. Measuring and benchmarking clinical performance. 2013 [cited 2017 15th February]; Available from: https://www.ahrq.gov/professionals/prevention-chronic-care/ improve/system/pfhandbook/mod7.html.

43. Ioannidis J, Patsopoulos N, Rothstein H. Research methodology: reasons or excuses for avoiding meta-analysis in forest plots. BMJ. 2008;336(7658):1413-5.

44. Ivers $\mathrm{N}$, et al. "My approach to this job is ... one person at a time": perceived discordance between population-level quality targets and patient-centred care. Can Fam Physician. 2014;60(3):258-66.

45. Institute of Medicine, The National Academies Collection: Reports funded by National Institutes of Health, in Patients Charting the Course: Citizen Engagement and the Learning Health System: Workshop Summary, L.A. Olsen, R.S. Saunders, and J.M. McGinnis, Editors. Washington (DC): National Academies Press (US). National Academy of Sciences; 2011

46. Brehaut JC, Eva KW. Building theories of knowledge translation interventions: use the entire menu of constructs. Implement Sci. 2012;7(1):114.

47. Ranmuthugala $\mathrm{G}$, et al. A realist evaluation of the role of communities of practice in changing healthcare practice. Implement Sci. 2011;6(1):1-6.

48. Kolehmainen N, McAnuff J. "I should have discharged him but I felt guilty": a qualitative investigation of clinicians' emotions in the context of implementing occupational therapy. Implement Sci. 2014:9(1):1-8.

49. Flottorp SA, et al. A checklist for identifying determinants of practice: a systematic review and synthesis of frameworks and taxonomies of factors that prevent or enable improvements in healthcare professional practice. Implement Sci. 2013:8(1):1-11.

50. Michie S, et al. Specifying and reporting complex behaviour change interventions: the need for a scientific method. Implement Sci. 2009:4(1):1-6.

51. Bhat N, Farias V, Moallemi C. Optimal ab testing. 2015.

52. Riley $\mathrm{BL}$, et al. Is reporting on interventions a weak link in understanding how and why they work? A preliminary exploration using community heart health exemplars. Implement Sci. 2008;3(1):1-12.

53. Conn LG, et al. Successful implementation of an enhanced recovery after surgery programme for elective colorectal surgery: a process evaluation of champions' experiences. Implement Sci. 2015;10(1):99.

54. Gunn JM, et al. Embedding effective depression care: using theory for primary care organisational and systems change. Implement Sci. 2010;5(1):62.

55. Hutchinson AM, et al. Implementation of an audit with feedback knowledge translation intervention to promote medication error reporting in health care: a protocol. Implement Sci. 2015;10(1):70. 